ISSN: $2536-5339$

\title{
Aktif Video Oyunları ve Wobble Board Denge Antrenmanının 6 Yaş Çocuklarda Dinamik Dengeye Etkisinin Karşılaştırılması ${ }^{1}$
}

\author{
Abdurrahman DEMiR ${ }^{2}$ \\ Manolya AKIN ${ }^{3}$ \\ ${ }^{2}$ Artvin Çoruh Üniversitesi, Beden Eğitimi ve Spor Yüksekokulu, ARTViN \\ ${ }^{3}$ Mersin Üniversitesi, Beden Eğitimi ve Spor Yüksekokulu, MERSiN
}

Künye: Demir, A. ve Akın, M. (2018). Aktif Video Oyunları ve Wobble Board Denge Antrenmanının 6 Yaş Çocuklarda Dinamik Dengeye Etkisinin Karşılaştırılması. Gaziantep Üniversitesi Spor Bilimleri Dergisi, 3(4): 109121.

\section{Öz}

Bu çalışmanın amacı, çocukların denge özelliklerini geliştirebileceği öngörülen aktif video oyunları ve hareketli zemin wobble bord denge antrenmanlarının etkisini inceleyerek karşılaştırmaktır. Araştırmaya, 6 yaşında 54 çocuk, Mersin Üniversitesi etik kurulundan izin alınarak katılmıştır. Çalışma benzer fiziksel özellikte 3 grupla yürütülmüştür. Denge antrenmanları 8 hafta 'wobble board' denge tahtası ve aktif video oyunları 'nintendo wii oyun konsolu' ile uygulanmıştır. Kontrol grubu ise herhangi bir fiziksel aktiviteye katılmayarak standart okul programına devam etmiştir. Tüm grupların ön-son test dinamik denge ölçümleri 'Techno-Body Cihazı' kullanılarak ölçülmüş, gruplar arasındaki farklara bakılmıştır. Parametrik sonuçlar için iki yönlü varyans analizi, non-parametrik sonuçlar için ise kruskall wallis' testi kullanılmıştır. Ön test ölçümlerde gruplar arasında anlamlı bir fark olmadığı görülmüştür $(p>, 05)$. Antrenmanlar sonrası ölçümlerde dinamik denge gelişimi açısından aktif video oyunu ile wobble board denge grupları arasında anlamlı fark bulunmamıştır $(p>, 05)$. Antrenman yapmayan kontrol grubunda ise dinamik denge gelişimi gözlenmemiş ve diğer gruplar arasındaki fark, istatistiksel olarak anlamlı bulunmuştur $(p<, 01)$. Hem wobble board hem de aktif video oyunları ile yapılan denge antrenmanlarının çocuklarda dinamik dengeyi benzer şekilde geliştirdiği bulunmuştur. Bu sonuca göre, ülkemizde sportif amaçlı olarak henüz kullanılmayan aktif video oyunlarının alternatif bir yöntem olarak kullanılabileceği önerilebilir.

\section{Orijinal Makale}

\section{Yayın Bilgileri}

Gönderi Tarihi: 20.09.2018

Kabul Tarihi: 20.11.2018

Yayın Tarihi: 28.12.2018

Mersin Üniversitesi BAP

\section{Sorumlu Yazar}

e-mail: manolya@mersin.edu.tr

DOI: $10.31680 /$ gaunjss.461858

Anahtar Kelimeler: Aktif video oyunu, Wobble Board, Dinamik denge

\section{Comparison of Active Video Games and Wooble Board Balance Training Effect on Dynamic Balance in 6 Years Old Children}

\begin{abstract}
The aim of this study is to compare the effects of active video games and moving floor wobble board equilibrium trainings which are predicted to improve the balance characteristics of children. 54 children, 6 years old, participated in the study with permission from the ethics committee of Mersin University. The study was carried out with 3 groups with similar physical characteristics. Balance training was carried out for 8 weeks with wobble board and active video games with the nintendo wii game console. The control group did not participate in any physical activity but continued with the standard school program. The pre-posttest dynamic balance measurements of all groups were measured using the 'Techno-Body Device test and the differences between the groups were examined. Two-way analysis of variance was used for parametric results and kruskall wallis test was used for non-parametric results. There was no significant difference between the groups in pre-test measurements $(p>, 05)$. There was no significant difference between active video game and wobble board balance groups in terms of dynamic balance development in post-training measurements $(p>, 05)$. In the non-training control group, dynamic balance development was not observed and the difference from the training groups was statistically significant $(p<, 05)$. It can be suggested that active video games, which are not yet used in our country, can be used as an alternative method due to the fact that both wobble board and active video games balance training developed the dynamic balance in children similarly.
\end{abstract}

Keywords: Active Video games, Wobble Board, Balance Training, Dynamic Balance

\section{Original Article}

\section{Article Info}

Received: 20.09 .2018

Accepted: 20.11 .2018

Published: 28.12.2018

\section{Corresponding Author}

e-mail: manolya@mersin.edu.tr

\footnotetext{
${ }^{1}$ Bu çalışma Abdurrahman Demir'in doktora çalışması olarak sunulmuş ve Mersin Üniversitesi BAP tarafından desteklenmiştir.
} 


\section{Giriş}

Aktif video oyunları (exergames), katılımcıların fiziksel hareketler yaparak oynamasını gerektiren video oyunlarıdır (Hansen ve Sanders, 2008). Eğlence ve egzersizin bir arada olduğu, oynayanların fiziksel olarak aktif hale gelmelerini sağlayan ve video oyunlarının her zaman oturarak yapıldığı algısını yıkan bir sistemdir. Gençlerin bu türde aktif video oynaması yönündeki eğilimleri, okul ortamı dâhil olmak üzere sağlıklı ve aktif bir yaşam biçimini geliştirmek için çekici bir seçenek haline gelmektedir (Graf ve ark., 2009). Araştırma sonuçları çocuklar tarafından kullanılan aktif video oyunlarının, çocukların serbest zamanlarında fiziksel aktivite seviyelerinde pozitif gelişmeler olduğunu ve sedanter davranışlarda azalma olduğunu göstermektedir (George ve ark., 2016). Sensör tabanlı teknolojileri içeren aktif video oyunları kullanıcıyı, oyunu vücut hareketleriyle kontrol etmeye, serbestçe hareket ettirmeye ve oynarken tüm ekstremitelerini kullanmaya olanak vermektedir. Çocukların, keyif aldıkları bir etkinlikte hareket etmeye teşvik edilmesi nedeniyle, aktif video oyunları umut verici bir fiziksel aktivite alternatifi olarak belirtilmektedir (Mellecker ve McManus, 2014).

Yakın zamanda oyun dünyası, Nintendo Wii Sports, Xbox Kinect ve PlayStation EyeToy gibi exergaming sistemlerinin piyasaya sürülmesiyle devrim yaratmıştır. Bu oyun sistemleri, oyunculara aktif olarak oyun oynama imkânı sunmakta olup, kısmen veya vücudun tamamının hareket etmesini gerektirmektedir. $\mathrm{Bu}$ nedenle, hareket etmeden oynanan klasik video oyunlarına kıyasla, kişilerin en azından günlük enerji harcamalarını artırmak açısından aktif video oyunları oynamaya teşvik etmenin faydalarının olabileceği makul görünmektedir (Vernadakis ve ark., 2012). Hem klinik hem de araştırma alanlarında uygulanan en popüler cihazlardan biri nintendo wii fit'tir. Wii fit, 2006 yılında piyasaya çıkmış ve üzerinde durulduğunda basınç merkezi üzerinden vücudun sallanmasını izleyen bir Wii denge tahtası cihazından oluşmaktadır. Oyuncular farklı mini oyunlar oynarken ekrandaki avatarı (Mii olarak adlandırılır) kontrol etmek için wii oyun konsoluna kablosuz olarak bağlanır (Cone ve ark., 2015). Bu oyunlar gerçek hayat, spor ve dans gibi aktiviteleri simüle edebilir.

Ayrıca antrenörler, sporcuları antrenmana güdülemek ve motive etmek için çeşitli yöntemler denemektedirler. Daha önceki çalışmalarda da aktif video oyunlarının motive edici özelliği ön planda olduğu belirtilmektedir (Brumels ve ark., 2008). Bu nedenle spor yaparken motive olmak ve eğlenceli bir şekilde sporu devam ettirme açısından aktif video oyunlarıyla yapılan çalışmalar önem kazanmaktadır. 
Aktif video oyunları ile geliştirilebileceği düşünülen ve sportif başarıda önemli olan biomotor yetilerden bir tanesi de dengedir. Denge, vücut stabilizesini koruma yeteneği ve dinamik hareketler boyunca postural kontrolü devam ettirme, sıçrama ve vurma gibi temel hareket becerilerinin başarılı yapılması için önemlidir (Spirduso ve ark., 1995). Bu nedenlerle denge sportif başarının anahtarı haline gelmiştir. Çocukların denge gelişiminde 3-6 yaş arasında görsel sisteme ek olarak somatosensör sistemin etkinliği de gelişir. Ayakta duruş pozisyonunda 6 yaşındaki çocuklar için hazırlayıcı ayarlamalar gelişmektedir (Forslund, 1992). Dengenin gerçekleştirilmesi için gerekli olan postural cevaplar, birçok eklemin koordineli bir şekilde birkaç sensor yapının karmaşık etkileşiminden kaynaklanmaktadır (Harringe ve ark., 2008).

Bu bilgiler ışığında Türkiye'de yapılan çalışmalara bakıldığında, aktif video oyunları ile ilgili araştırmaların klinik alanda fizyoterapistler tarafından yapıldığı, (Haksever, 2012; Çekok, 2014; Karasu, 2011; Ürgen, 2013; Aksoy, 2015; Ekici, 2017) spor branşları ya da çocuklar arasında herhangi bir çalışmanın yapılmadığı görülmüştür. Alternatif olabileceği düşünülen aktif video oyunlarının yanında hareketli zeminde yapılan denge antrenmanlarının da etkisi önemli görünmektedir. Sportif alanda denge becerisinin gelişimi ve aktif video oyunları ile ilişkisini yordayan çalışmalar sınırlı sayıdadır ve gelişen teknolojiyi yakalayarak daha sportif sağlıklı çocuklar yetiştirmek önemli görülmektedir.

\section{Yöntem}

Katılımcılar Helsinki kriterleri'ne göre bilgilendirilmiş olur alma formu ile velilerinden izin alınıp gönüllü olarak katılmıştır. Bu çalışma için Mersin Üniversitesi Fen Bilimleri Araştırmaları Etik Kurul'a başvurulmuş olup gerekli etik kurul izni 24/03/2017 tarihinde 2017/02 sayı numarası ile alınmıştır.

\section{Araştırmanın Modeli}

Bu çalışmanın amacı, aktif video oyunları ve hareketli zemin wobble board antrenmanlarının 6 yaşındaki çocukların dinamik denge gelişimlerine etkisini belirlemek ve iki antrenman yönteminin etkisini karşılaştırmaktır. Araştırmada, kontrol gruplu, öntest- sontest deneysel yansız örnekleme modeli kullanılmıştır. 


\section{Evren ve Örneklem}

Araştırma Şanlıurfa ili Eyyübiye ilçesinde bulunan Fatih Sultan Mehmet İlkokulunda öğrenim gören benzer özellikte çocuklardan, hareketli zemin wobble board, aktif video oyunu ve kontrol grubu olmak üzere 18 kişilik üç farklı gruptan oluşturulmuştur. Katılımcılar daha önceden herhangi bir branşla uğraşmamış ve spor yapmayan altı yaşındaki çocuklardan seçilmiştir.

\section{Veri Toplama Araçları}

Çalışmaya başlamadan önce Beden Kitle indeksi (BKI) değerlerinin dengeyi etkileyebileceği ön görüsünden hareketle, kilogram cinsinden vücut ağırlığının ve metre cinsinden boy uzunluğun karesine bölünmesiyle $(\mathrm{kg} / \mathrm{m} 2)$ hesaplanmıştır (WHO, 2017). Türk standartlarında beden kitle indeksi referans değerleri kullanılmış (Neyzi ve ark.2015) ve aşırı zayıf, aşırı kilolu örnekler çalışmaya alınmamıştır. Katılımcıların yaş, vücut ağırlığı, boy ve beden kitle indeksi değerleri Tablo 1'de verilmiştir.

Tablo 1. Yaş, Boy, Kilo ve BKI Ortalama Değerleri

\begin{tabular}{lccccc}
\hline & $\boldsymbol{n}$ & \multicolumn{1}{c}{ Yaş } & \multicolumn{1}{c}{ Kilo } & \multicolumn{1}{l}{ Boy } & BKi \\
\hline Wobble Board Grubu & 18 & 6,25 & 20,9 & 116,3 & 15,4 \\
Aktif Video Grubu & 18 & 6,22 & 21,4 & 116,5 & 15,7 \\
Kontrol Grubu & 18 & 6,18 & 21,6 & 117,6 & 15,6 \\
Toplam & 54 & 6,21 & 21,3 & 116,8 & 15,6 \\
\hline
\end{tabular}

BKí=Beden Kütle İndeksi;

\section{Uygulanan Antrenman Programları}

Antrenmanlar haftada üç gün 45 dakika ve toplamda 8 hafta uygulamalı yaptırılmıştır. Kontrol grubu ise, normal okul aktivitelerine devam etmiştir.

a. Nintendo Wii Aktif Video Oyunu: Wii fit, genç ve yaşlı herkes için tasarlanmış fitness ve eğlenceyi birleştiren aktif video oyunudur. Wii Fit; wii oyun konsolu, wii remote, nonchuck, alıcı çubuğu ve balance boardtan (denge tahtasından) oluşmaktadır (Wiifit, 2007). Çalışmada 8 hafta boyunca uygulanan aktif video oyunları Tablo 2'de ve Nintendo Wii oyun konsolu şekil 1'de verilmiştir. 
Tablo 2. Uygulanan Aktif Video Oyunları Programı

\begin{tabular}{cl|l}
\hline 1. & Hafta & Kafa Topu- Tightrope Tension \\
\hline 2. & Hafta & Table Tilt-Kayak Atlama \\
\hline 3. & Hafta & Penguen Kayış-Snowboard Slalom \\
\hline 4. & Hafta & Denge Balonu-Kayak Slalom \\
\hline 5. & Hafta & Kafa Topu- Tightrope Tension \\
\hline 6. & Hafta & Table Tilt-Penguen Slide \\
\hline 7. & Hafta & Penguen Kayış-Snowboard Slalom \\
\hline 8. & Hafta & Denge Balonu-Kayak Slalom \\
\hline
\end{tabular}

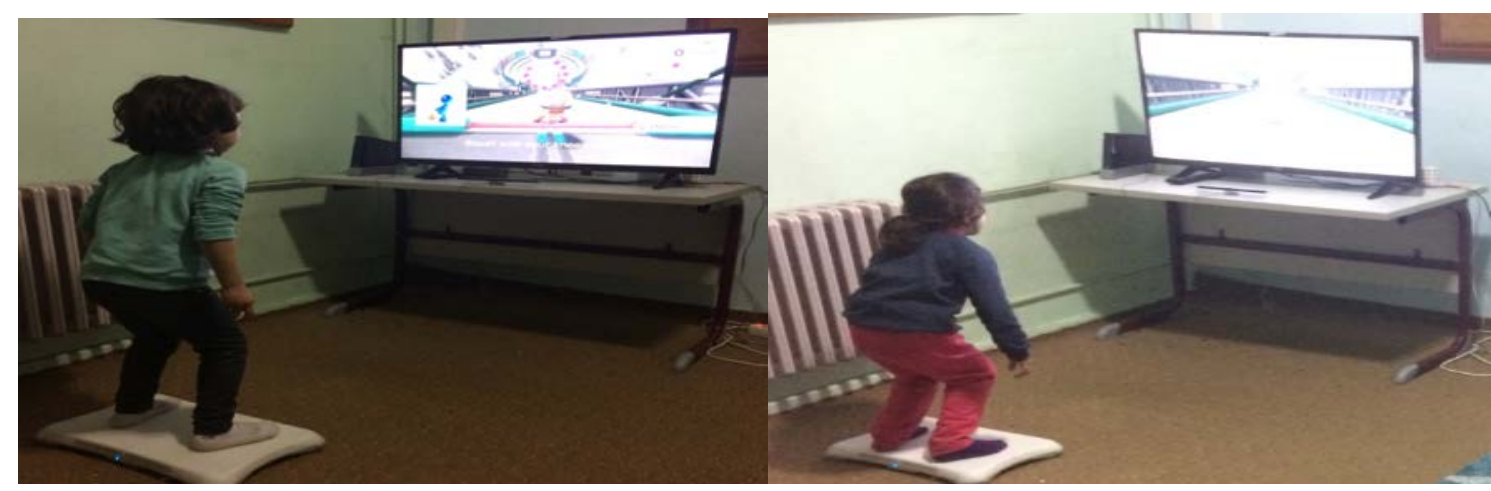

Şekil 1. Nintendo Aktif Video Oyunu

b. Wobble Board: Düz bir zemin üzerinde kişiyi hareket ettirerek çalışmasını sağlayacak şekilde tasarlanmıştır. Böylece, kişi üstünde dururken sallanır ve bu sayede snow board ya da kaykay tahtası gibi kendi ekseni etrafında dönerek hareket eder. Wobble boardların hepsi merkezi destek noktasının değişmesi ve zeminde hareket etmesi prensibine sahiptir. Wobble board uygulanması oldukça basit ve düzenli bir denge duyusunu gerektirir (Guidry, 1996). Uygulanan wobble board antrenman programı Tablo 3'te verilmiştir.

Tablo 3. Uygulanan Wobble Board Antrenman Programı

\begin{tabular}{ll|l}
\hline 1. & Hafta & Zeminde tek ayak duruş \\
\hline 2. & Hafta & Wobble board üzerinde tek-çift ayak duruş \\
\hline 3. & Hafta & Wobble board üzerinde diz bükme \\
\hline 4. & Hafta & Zeminde ve wobble board üzerinde küçük adımlar atma \\
\hline 5. & Hafta & Zeminde gözler kapalı kalça fleksiyon duruşu \\
\hline 6. & Hafta & Zeminde ve wobble board üzerinde top atma \\
\hline 7. & Hafta & Wobble board üzerinde gözler açık-kapalı diz bükme \\
\hline 8. & Hafta & Zeminde ve wobble board üzerinde gözler açık-kapalı ayak ucunu tutma \\
\hline
\end{tabular}




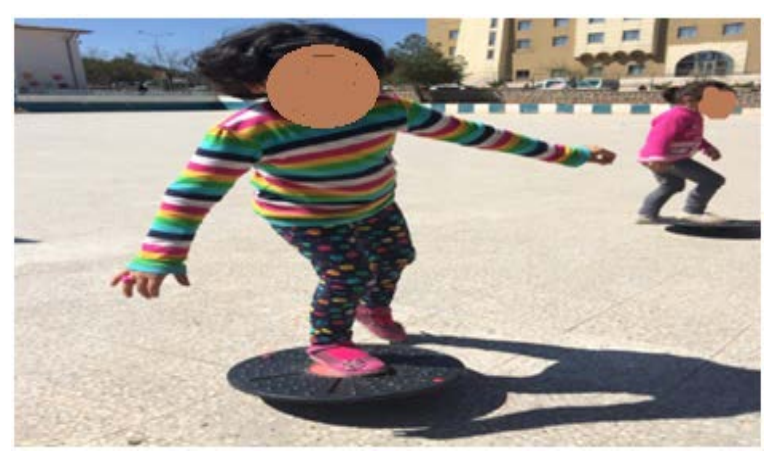

Şekil 2. Wobble Board

\section{Dinamik Denge Ölçüm Yöntemi}

Techno body denge cihazı; gözler açık bir şekilde çift ayakla ve tek ayakla (sağ-sol) dinamik dengeyi ölçen elektronik bir denge ölçüm cihazıdır. Araştırmamızda, kolay ölçüm başığı kullanıldı. Test çift ayakla kollar açık ölçüm yapıldığında otuz saniye, sağ ve sol tek ayakla yapılan ölçümlerde ise on saniye olarak uygulandı. Katılımcılar dengelerini kaybedip düştüğünde ya da süresi bitmeden platformdan indiğinde test tekrarlandı. Test iki kez uygulandı ve en iyi sonuç alındı. Test sonucu daire içinde kat edilen mesafe Perimeter Length (Çevre uzunluğu), öne-arkaya salınım (Medium Equilibrium Center-AP) ve yanlara salınım (Medium Equilibrium Center-ML) değerleri istatistiksel analizler için kullanılmıştır (Akın, 2013).
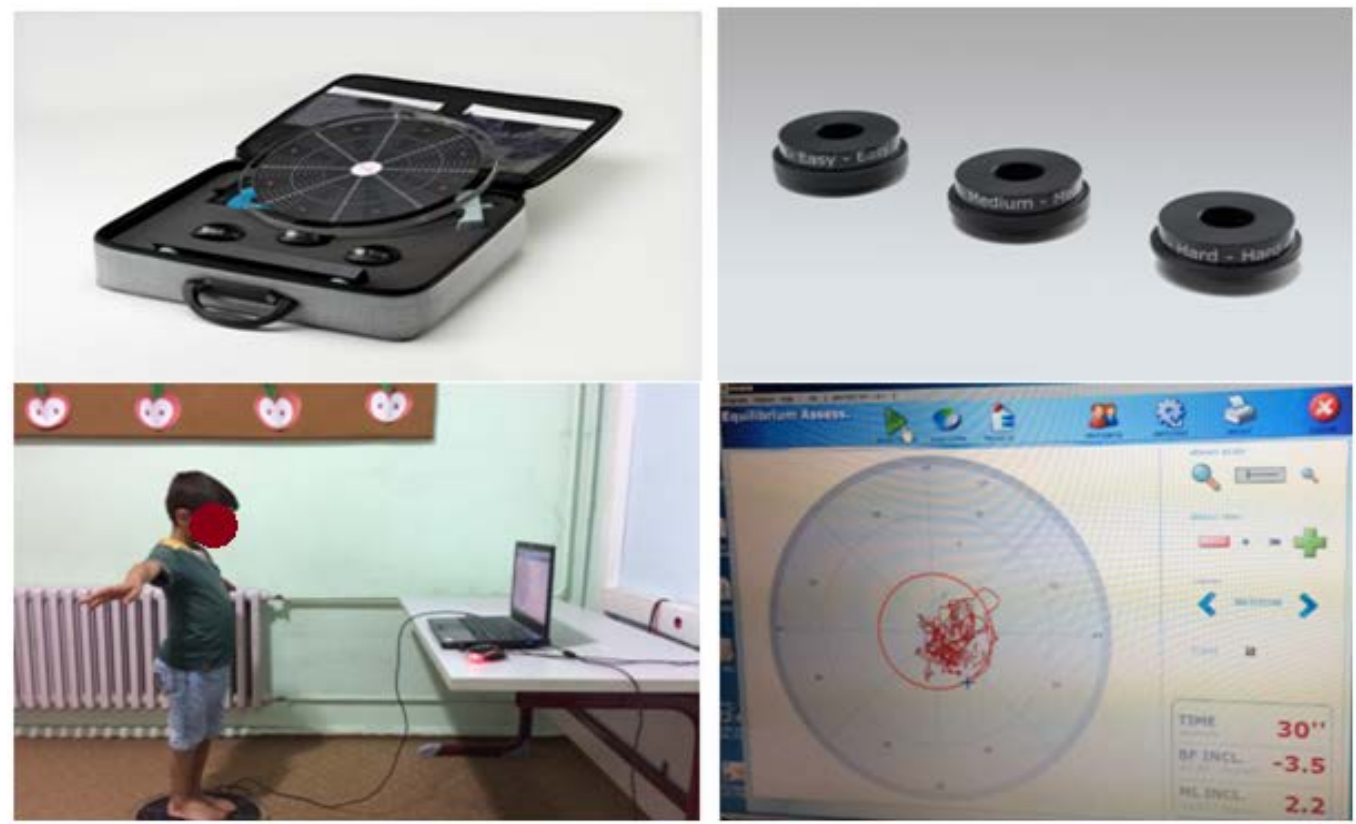

Şekil 3. Techno Body Ölçüm Cihaz 


\section{Verilerin Analizi}

Katılımcıların yaş, boy, kilo ve beden kitle indekslerinin belirlenmesi için betimsel istatistikten yararlanılmıştır. Normallik dağılımları için shapiro wilk testi uygulanmıştır ( $p>, 05)$. Tüm ölçümlerde dağılım normal olduğundan ön test için tek yönlü varyans analizi kullanıldı. Ön test ve son test sonuçları arasındaki farka bakmak için de parametrik dağılımlarda iki yönlü Anova analizi kullanılmıştır. Çalışmada, anlamlılık düzeyi olarak istatistiksel işlemlerde 0,05 kullanılmıştır.

\section{Bulgular}

Araştırmaya katılan öğrencilerin dinamik denge ön test ve son test analizi Tablo 4'de verilmiştir.

Tablo 4. Grupların Dinamik Denge Ön Test Son Test Analizi

\begin{tabular}{|c|c|c|c|c|c|c|c|c|c|c|c|}
\hline & \multicolumn{3}{|c|}{ Wobble Board Grubu } & \multicolumn{3}{|c|}{ Aktif Video Oyunu } & \multicolumn{3}{|c|}{ Kontrol Grubu } & \multirow[b]{2}{*}{$\mathrm{p}$} & \multirow[b]{2}{*}{ Fark } \\
\hline & $\mathrm{n}$ & $\begin{array}{c}\bar{X} \\
\text { (Ön Test) }\end{array}$ & $\begin{array}{c}\bar{X} \\
\text { (Son Test) }\end{array}$ & $n$ & $\begin{array}{c}\bar{X} \\
\text { (Ön Test) }\end{array}$ & $\begin{array}{c}\bar{X} \\
\text { (Son Test) }\end{array}$ & $\mathrm{n}$ & $\begin{array}{c}\bar{X} \\
\text { (Ön Test) }\end{array}$ & $\begin{array}{c}\bar{X} \\
\text { (Son } \\
\text { Test) }\end{array}$ & & \\
\hline PL-Çift & 18 & 650,07 & 292,11 & 18 & 602,46 & 280,47 & 18 & 301,10 & 577,75 &, $001 *$ & $\begin{array}{l}1-3 ; \\
2-3\end{array}$ \\
\hline PL-Sağ & 18 & 343,83 & 125,65 & 18 & 301,63 & 140,11 & 18 & 338,58 & 297,57 &, $000^{*}$ & $\begin{array}{l}1-3 ; \\
2-3\end{array}$ \\
\hline PL-Sol & 18 & 329,40 & 137,82 & 18 & 309,53 & 146,94 & 18 & 344,97 & 307,15 &, $000^{*}$ & $\begin{array}{l}1-3 \\
2-3\end{array}$ \\
\hline Mec-Ap Çift & 18 &,- 42 &,- 11 & 18 & ,31 &,- 06 & 18 & $-1,23$ & 13 & ,352 & - \\
\hline Mec-Ap Sağ & 18 & $-1,22$ & ,38 & 18 &,- 42 &,- 60 & 18 &,- 58 &,- 57 & ,953 & - \\
\hline Mec-Ap Sol & 18 & $-1,44$ & $-1,18$ & 18 & ,80 &,- 68 & 18 &,- 44 & $-1,60$ & ,051 & - \\
\hline Mec-MI-Çift & 18 & $-1,15$ & $-2,36$ & 18 & $-1,96$ & $-1,47$ & 18 & $-1,72$ & $-1,96$ & 976 & - \\
\hline Mec-MI Sağ & 18 & $-1,62$ & $-2,44$ & 18 & $-1,44$ & $-2,74$ & 18 & $-2,10$ & $-2,10$ & ,991 & - \\
\hline Mec-MI Sol & 18 & $-1,50$ & $-1,18$ & 18 &,- 76 &,- 68 & 18 & $-1,26$ & $-1,60$ & ,462 & - \\
\hline
\end{tabular}

Tablo 2 incelendiğinde, çift sağ sol ayakla yapılan teste öne geri salınım (Mec-Ap) ve yana salınım (Mec-ML) değerleri arasında antrenman grupları ve kontrol gruplarında anlamlı fark olmadığı görülmektedir. Çift sağ ve sol ayakla kat edilen mesafe (PL) değerlerinde ise kontrol grubu ile antrenman grupları arasında farklılık istatistiksel olarak anlamlı bulunmuştur. Bu sonuçlara göre, wobble board grubuna uygulan wobble board denge antrenmanının ve aktif video grubuna uygulanan nintendo wii fit denge oyunlarının dinamik dengeyi aynı oranda geliştirdiği görülmektedir.

\section{Tartışma ve Sonuç}

Çalışmada uygulanan aktif video oyunları ve wobble board denge antrenmanlarının 6 yaş grubu çocuklar üzerinde dinamik dengeyi benzer şekilde geliştirdiği sonucuna varılmıştır. Daha önce yapılan araştırmalarda çalışmamızı 
destekleyen bulgular görülmüştür (Goble ve ark., 2014; Sheehan ve Katz, 2013; Sheehan ve Katz, 2012; Vernadakis ve ark., 2014). Bu araştırmaların sonuçlarına göre aktif video oyunlarıyla yapılan denge çalışmalarında bu yaş grubundaki çocukların denge performanslarını geliştirdiği söylenebilir. 2014 yılında yapılan bir incelemede, aktif video oyunlarının, hem sağlıklı hem de klinik popülâsyonda genel dengeyi iyileştirmek için etkili olduğunu göstermiştir (Goble ve ark., 2014).

Denge gelişiminin yanı sıra aktif video oyunlarının çocukların diğer motorik özelliklerine etkisini inceleyen araştırmalar (Gao ve ark., 2013; Barnett ve ark., 2012; Vernadakis ve ark., 2015; White ve ark., 2011; George ve ark., 2016; LanninghamFoster ve ark., 2009; Sun, 2012; Sun, 2016; Lwin ve Malik, 2012; Johnson ve ark., 2016) ve enerji harcanması ile ilgili çalışmalar (Graves ve ark, 2008; Graf ve ark., 2009; Lanningham-Foster ve ark., 2006; Mellecker, \& McManus, 2008; Maddison ve ark., 2007) yapıldığı görülmektedir. Bu araştırmalarda aktif video oyunları ile ilgili olumlu sonuçlar bulunmuştur. Yapılan araştırmaların sonuçlarına ve bu çalışmanın sonucuna bakarak aktif video oyunlarının çocuklar üzerinde olumlu etkilerinin olduğu söylenebilir.

Klasik denge antrenmanlarının da çocukların denge gelişimlerine olumlu yönde katkıda bulunduklarını belirten ve yapılan bu çalışmayı destekleyen araştırmalar mevcuttur (Atılgan ve ark., 2012; Granacher ve ark., 2010; Günebakan ve ark., 2009; Granacher ve ark., 2011; Kidgell ve ark., 2007; Kesilmiş ve Akın, 2016).

Kritik yaş dönemlerine göre hazırlanan antrenman programlarının çocukların gelişimlerine pozitif yönde katkı sağladığı ve beceri gelişimlerini hızlandırdığı bilinmektedir (Tüfekçioğlu, 2008). 6 yaşındaki çocukların motor gelişim yönünden gelişme çağında olması nedeniyle, bu dönemde öğrenilen beceriler daha sonraki dönemlerde kazanılacak olan hareket becerileri için öncül olmaktadır (San Bayhan ve Artan, 2004). Spora erken yaşlarda başlayan çocuklar için seçilen antrenmanların, onların olgunluk düzeylerine ulaşmasına engel olmayacak bir biçimde olmasına özen gösterilmelidir. Bu yüzden okul öncesi çocuklara yaptırılacak hareketler çocukların hazır bulunuşluk seviyelerine uygun olarak hazırlanmalı ve aşamalı olarak hedefe varmak amaçlanmalıdır (Atilgan, 2012). Bu çalışmalardan yola çıkarak denge gelişiminin erken yaşlardaki önemi dikkate alındığında, okul öncesi çocuklarına uygulanacak olan sportif antrenmanlarda denge çalışmalarının gerekliliği öne çıkmaktadır. Bu yüzden çocukların hafif yoğunlukta sıkılmadan ve eğlenerek 
yapabilecekleri aktif video oyunları gibi alternatif antrenmanlar çocukların denge performansları için önemli seçenek olabilir.

$\mathrm{Bu}$ araştırmalardan yola çıkarak denge gelişiminin küçük yaş grupları üzerindeki önemi dikkate alındığında, okul öncesi çocuklarına uygulanacak olan sportif aktivitelerde denge antrenmanlarının gerekliliği ön plana çıkmaktadır. Bu yüzden çocukların hafif düzeyde sıkılmadan ve eğlenerek yapabilecekleri aktif video oyunları gibi alternatif aktiviteler çocukların denge gelişimi için önemli seçenekler olabilir.

Sonuçta, uygulama sonrasında yapılan test sonuçlarına göre hem aktif video oyunlarının hem de wobble board denge antrenmanlarının çocukların denge seviyelerinde bir artış meydana getirdiği gözlemlenmiştir. Araştırmada aktif video oyunu grubu ve Wobble Board denge antrenmanları grubu antrenman öncesi sonrası dinamik denge değerleri arasındaki fark gelişimsel olarak anlamlı bulunurken iki grubun kendi arasındaki farkın anlamlı olmadığı bulunmuştur. Antrenman yapmayan kontrol grubunda ise antrenman etkisi ön test son test dinamik denge sonuçları arasında anlamlı fark bulunmamıştır. Üç grubun son test dinamik denge değerlerine baktığımızda aktif video oyun grubu ve Wobble Board denge antrenmanı gruplarının kontrol grubuyla ayrı ayrı anlamlı fark ortaya çıkmıştır. Buna göre uygulanan aktif video oyunları ve Wobble Board denge antrenmanlarının bu yaş grubundaki çocukların denge becerileri üzerindeki gelişim açısından etkin oldukları sonucuna varılmıştır. Bu bulgulara göre yapılan araştırmada 8 haftalık aktif video oyunlarının 6 yaş grubu çocuklarda wobble board ile yapılan denge antrenmanları kadar etkili olduğu görülmektedir. Bu bağlamda, kapalı alanda yapılabilen ve motivasyonel olarak çocuklar tarafından eğlenceli bulunan aktif video oyunları, dengeyi geliştirmek için alternatif bir yöntem olduğu söylenebilir.

\section{Kaynaklar}

Akın, M. (2013). Effect of gymnastics training on dynamic balance abilities in 4-6 years of age children. International Journal of Academic Research, 5(2).

Aksoy, C,C. (2015). Diz Ekleminde Kronik Ortopedik Problemi Olan Hastalarda Nintendi Wii ile Yapılan Eğitimin Dengeye Etkisinin İncelenmesi. Pamukkale Üniversitesi, Sağlık Bilimleri Enstitüsü, Fizik Tedavi ve Anabilim Dalı, Yayınlanmamış Doktora Tezi, Denizli. 
Atılgan, O. E., Akın, M., Alpkaya, U. ve Pınar, S. (2012). Elit bayan cimnastikçilerin denge aletindeki denge kayıpları ile denge parametreleri arasındaki ilişkinin incelenmesi. International Journal of Human Sciences, (9)2: 1260-1271

Atilgan, O. E. (2012). Relationships between perceptual-motor skills and postural balance in nine years old boys. Educational Research and Reviews, 7(24), 517525.

Barnett, L. M., Hinkley, T., Okely, A. D., Hesket, K., \& Salmon, J. O. (2012). Use of electronic games by young children and fundamental movement skills. Perceptual and motor skills, 114(3), 1023-1034.

Brumels, K. A., Blasius, T., Cortright, T., Oumedian, D., \& Solberg, B. (2008). Comparison of efficacy between traditional and video game based balance programs. Clinical Kinesiology: Journal of the American Kinesiotherapy Association, 62(4), 26-32.

Cone, B. L., Levy, S. S., \& Goble, D. J. (2015). Wii Fit exer-game training improves sensory weighting and dynamic balance in healthy young adults. Gait \& posture, 41(2), 711-715.

Çekok, F, B. (2014)Hemiplejik Hastalarda Nintendo Wii Oyunlarının Denge ve Üst Ekstremite Fonksiyonlarına Etkisi. Dokuz Eylül Üniversitesi, Sağlık Bilimleri Enstitüsü, Nörolojik Fizyoterapi-Rehabilitasyon Yüksek Lisans Tezi, İzmir.

Ekici, D, K. (2017). Bağımsız Yürüyen Serebral Palsili Çocuklarda Nintendo Wii Fit Eğitiminin Denge Üzerine Etkileri. Yeditepe Üniversitesi, Sağlık Bilimleri Enstitüsü, Fizik Tedavi ve Rehabilitasyon Anabilim Dalı, Yayınlanmamış Yüksek Lisans Tezi, İstanbul.

Forslund, M. (1992). Growth and motor performance in preterm children at 8 years of age. Acta Paediatrica, 81(10), 840-842.

Gao, Z., Zhang, T., \& Stodden, D. (2013). Children's physical activity levels and psychological correlates in interactive dance versus aerobic dance. Journal of Sport and Health Science, 2(3), 146-151.

George, A. M., Rohr, L. E., \& Byrne, J. (2016). Impact of Nintendo Wii games on physical literacy in children: Motor skills, physical fitness, activity behaviors, and knowledge. Sports, 4(1), 3.

Goble, D. J., Cone, B. L., \& Fling, B. W. (2014). Using the Wii Fit as a tool for balance assessment and neurorehabilitation: the first half decade of "Wiisearch". Journal of neuroengineering and rehabilitation, 11(1), 12. 
Graf, D. L., Pratt, L. V., Hester, C. N., \& Short, K. R. (2009). Playing active video games increases energy expenditure in children. Pediatrics, 124(2), 534-540.

Granacher, U., Gollhofer, A., \& Kriemler, S. (2010). Effects of balance training on postural sway, leg extensor strength, and jumping height in adolescents. Research quarterly for exercise and sport, 81(3), 245-251

Granacher, U., Muehlbauer, T., Maestrini, L., Zahner, L., \& Gollhofer, A. (2011). Can balance training promote balance and strength in prepubertal children. The Journal of Strength Conditioning Research, 25(6), 1759-1766.

Graves, L., Stratton, G., Ridgers, N. D., \& Cable, N. T. (2008). Energy expenditure in adolescents playing new generation computer games. British journal of sports medicine, 42(7), 592-594.

Haksever B. (2012). Hamstring tendon grefti ile ACL rekonstrüksiyonu sonrası Wii terapi ile standart rehabilitasyon protokolünün karşılaştırılması. Hacettepe Üniversitesi, Sağlık Bilimleri Enstitüsü, Spor Fizyoterapistliğl Programı Yüksek Lisans Tezi, Ankara.

Hansen, L., Sanders, S. (2008). Interactive gaming: Changing the face of fitness. Florida Alliance for Health, Physical Education, Recreation, Dance \& Sport Journal, 46(1), 38-41.

Harringe, M. L., Halvorsen, K., Renström, P., \& Werner, S. (2008). Postural control measured as the center of pressure excursion in young female gymnasts with low back pain or lower extremity injury. Gait \& posture, 28(1), 38-45.

Johnson, T. M., Ridgers, N. D., Hulteen, R. M., Mellecker, R. R., \& Barnett, L. M. (2016). Does playing a sports active video game improve young children's ball skill competence.. Journal of science and medicine in sport, 19(5), 432-436.

Karasu, A, U. (2011). Hemiplejide Nintendo Wii İle Sanal Gerçeklik Uygulamalarının Denge Üzerine Etkisi: Randomize Kontrollü Çalışma.Uzmanlık Tezi.Gazi Üniversitesi Tıp Fakültesi, Fiziksel Tıp ve Rehabilitasyon Anabilim Dalı, Uzmanlık Tezi, Ankara.

Kesilmiş, İ., Akın, M. (2016). Dört-Altı Yaş Çocuklarda Jimnastik Antrenmanının Biyomotor Yetiler Üzerine Etkisi. Turkiye Klinikleri Journal of Sports Sciences, 8(1), 15-21.

Kidgell, D. J., Horvath, D. M., Jackson, B. M., \& Seymour, P. J. (2007). Effect of six weeks of dura disc and mini-trampoline balance training on postural sway in athletes with functional ankle instability. Journal of Strength and Conditioning Research, 21(2), 466. 
Lanningham-Foster, L., Foster, R. C., McCrady, S. K., Jensen, T. B., Mitre, N., \& Levine, J. A. (2009). Activity-promoting video games and increased energy expenditure. The Journal of pediatrics, 154(6), 819-823.

Lanningham-Foster, L., Jensen, T. B., Foster, R. C., Redmond, A. B., Walker, B. A., Heinz, D., \& Levine, J. A. (2006). Energy expenditure of sedentary screen time compared with active screen time for children. Pediatrics, 118(6), e1831e1835.

Lwin, M. O.,\& Malik, S. (2012). The efficacy of exergames-incorporated physical education lessons in influencing drivers of physical activity: a comparison of children and pre-adolescents. Psychology of Sport and Exercise, 13(6), 756760.

Maddison, R., Mhurchu, C. N., Jull, A., Jiang, Y., Prapavessis, H., \& Rodgers, A. (2007). Energy expended playing video console games: an opportunity to increase children's physical activity?. Pediatric exercise science, 19(3), 334343.

Mellecker, R. R., \& McManus, A. M. (2008). Energy expenditure and cardiovascular responses to seated and active gaming in children. Archives of pediatrics \& adolescent medicine, 162(9), 886-891.

Mellecker, R. R., \& McManus, A. M. (2014). Active video games and physical activity recommendations: A comparison of the Gamercize Stepper, XBOX Kinect and XaviX J-Mat. Journal of science and medicine in sport, 17(3), 288-292.

Neyzi, O., Bundak, R., Gökçay, G., Günöz, H., Furman, A., Darendeliler, F., \& Baş, F. (2015). Reference values for weight, height, head circumference, and body mass index in Turkish children. Journal of clinical research in pediatric endocrinology, 7(4), 280.

San Bayhan, P.,\& Artan, İ. (2004). Çocuk gelişimi ve eğitimi. Morpa Kültür Yayınları.

Sarlegna, F. R.,\& Sainburg, R. L. (2009). The roles of vision and proprioception in the planning of reaching movements. In Progress in Motor Control (pp. 317-335). Springer US.

Sheehan, D. P., \& Katz, L. (2012). The Impact of a Six Week Exergaming Curriculum on Balance with Grade Three School Children using the Wii $\mathrm{FIT}+{ }^{\mathrm{TM}}$. International Journal of Computer Science in Sport (International Association of Computer Science in Sport), 11(3). 
Sheehan, D. P., \& Katz, L. (2013). The effects of a daily, 6-week exergaming curriculum on balance in fourth grade children. Journal of Sport and Health Science, 2(3), 131-137.

Spirduso, W. W., Francis, K. L., \& MacRae, P. G. (1995). Physical dimensions of aging. Human Kinetics. Champaign. Illinois. USA.

Sun, H. (2012). Exergaming impact on physical activity and interest in elementary school children. Research quarterly for exercise and sport, 83(2), 212-220

Sun, H.,\& Gao, Y. (2016). Impact of an active educational video game on children's motivation, science knowledge, and physical activity. Journal of Sport and Health Science, 5(2), 239-245

Tüfekçioğlu, E. (2008). Okul öncesi 4-6 yaş çocuklarında algısal motor gelişim programlarının denge ve çabukluk üzerine etkisi. Uluslararası İnsan Bilimleri Dergisi, 5(2).

Ürgen S, M. (2013). Hemiparatik Serebral Palsili Çocuklarda Sanal Gerçeklik Yönteminin Denge ve İleri Düzey Motor Beceriler Üzerine Olan Etkisinin Incelenmesi. Hacettepe Üniversitesi, Sağlık Bilimleri Enstitüsü Fizik Tedavi Ve Rehabilitasyon Programı Yüksek Lisans Tezi, Ankara.

Vernadakis, N., Gioftsidou, A., Antoniou, P., loannidis, D., \& Giannousi, M. (2012). The impact of Nintendo Wii to physical education students' balance compared to the traditional approaches. Computers \& Education, 59(2), 196-205.

Vernadakis, N., Kouli, O., Tsitskari, E., Gioftsidou, A., \& Antoniou, P. (2014). University students' ability-expectancy beliefs and subjective task values for exergames. Computers \& Education, 75, 149-161.

Vernadakis, N., Papastergiou, M., Zetou, E., \& Antoniou, P. (2015). The impact of an exergame-based intervention on children's fundamental motor skills. Computers \& Education, 83, 90-102.

White, K., Schofield, G., \& Kilding, A. E. (2011). Energy expended by boys playing active video games. Journal of science and medicine in sport, 14(2), 130-134.

Who, (2017). Body mass index - BMI. 16/12/2017 tarihinde http://www.euro.who.int/en/health-topics/disease-prevention/nutrition/a-healthy/body-mass-index-bmi. adresinden erişildi. 